Received: 10 March 2017

Accepted: 14 August 2017

Published online: 13 September 2017

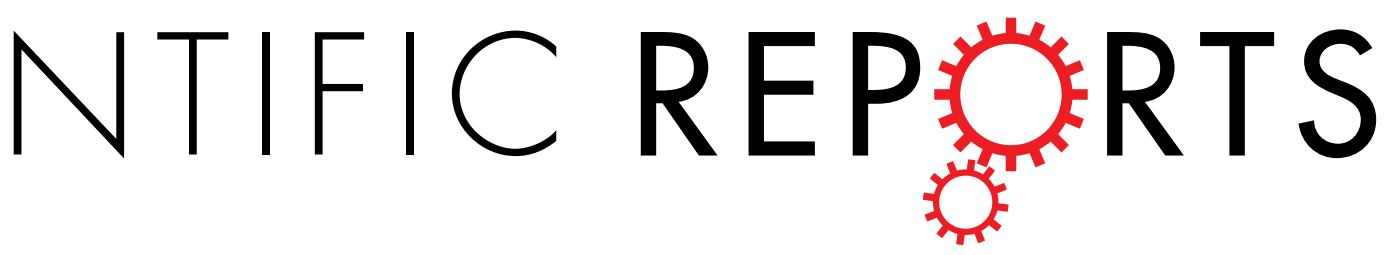

\title{
OPEN A Plastid-Localized Pentatricopeptide Repeat Protein is Required for Both Pollen Development and Plant Growth in Rice
}

\author{
Yu-Jun Liu ${ }^{1,2}$, Xuejiao Liu ${ }^{1}$, Hao Chen ${ }^{1}$, Peng Zheng ${ }^{1}$, Wenyi Wang ${ }^{1}$, Liangchao Wang ${ }^{1}$, \\ Jianhua Zhang ${ }^{2} \&$ Jumin Tu${ }^{1}$
}

Several mitochondrial-targeted pentatricopeptide repeat (PPR) proteins involved in pollen development have been reported to be fertility restorer (Rf) proteins. However, the roles of plastidlocalized PPR proteins in plant male reproduction are poorly defined. Here, we described a plastidlocalized PPR-SMR protein, OsPPR676, which is required for plant growth and pollen development in rice. In this study, OsPPR676 was confirmed to be an interacted protein with Osj10gBTF3, $\beta$-subunit of nascent polypeptide-associated complex ( $\beta$-NAC), by bimolecular fluorescence complementation assays, indicating that both proteins are probably involved in the same regulatory pathway of pollen development. Compared with other chloroplast-rich tissues, OsPPR676 was only weakly expressed in anther, but in the Mei and YM stages of pollen development, its expression was relatively strong in the tapetum. Disruption of OsPPR676 resulted in growth retardation of plants and partial sterility of pollens. Phenotypic analysis of different osppr676 mutant lines implied that the SMR domain was not essential for the function of OsPPR676. We further demonstrated that OsPPR676 is essential for production of plastid atpB subunit, and then plays crucial roles in biosynthesis of fatty acids, carbohydrates, and other organic matters via affecting activity of ATP synthase.

Rice is not only an important monocot model for biological studies, but also a crop of global economic and agronomic significance. It is estimated that the world rice production of 2015 was approximately 490.1 million metric tons (FAOstat, 2016; http://faostat.fao.org/), and this forms the staple food for more than half of the world's population ${ }^{1}$. Over the past 30 years, the importance of hybrid rice has clearly been demonstrated with yield increases of approximately $20 \%$ over that of inbred rice ${ }^{2}$. Controlling the process of male reproduction is critical for selective breeding, the release of genetically modified (GM) pollen, and the commercial development of hybrid lines.

Rice male sterility is frequently caused by environmental effects or genetic mutation, leading to defective anther development and pollen fertility. The study of the genes involved in pollen development has principally focused on model plants Arabidopsis and more recently on rice ${ }^{3,4}$. Cytoplasmic male sterility (CMS), a condition under which a plant is unable to produce functional pollen, is widespread among higher plants. A specific set of nuclear genes called restorer-of-fertility (Rf) genes, which primarily belong to the pentatricopeptide repeat (PPR) family, are required for the development of a functional male gametophyte in plants with $S$ (sterile) type cytoplasm. In majority of cases, Rf-related PPR proteins can restore CMS phenotype by reducing the accumulation of CMS-associated RNAs and/or proteins. For example, RF1A and RF1B are both targeted to mitochondria and can restore rice male fertility by blocking ORF79 production via endonucleolytic cleavage (RF1A) or degradation (RF1B) of dicistronic B-atp6/orf79 mRNA $^{5}$. Another PPR protein RF5 interacts directly with a Gly-rich protein GRP162 to form a subunit of restorer fertility complex (RFC), binding to CMS-associated transcripts atp6/orfH79

${ }^{1}$ Institute of Crop Science, College of Agriculture and Biotechnology, Zhejiang University, Hangzhou, 310058, P. R. China. 'State Key Lab of Agrobiotechnology, School of Life Science, The Chinese University of Hong Kong, N.T., Hong Kong, P. R. China. Yu-Jun Liu and Xuejiao Liu contributed equally to this work. Correspondence and requests for materials should be addressed to J.Z. (email: jhzhang@cuhk.edu.hk) or J.T. (email: jtu@zju.edu.cn) 


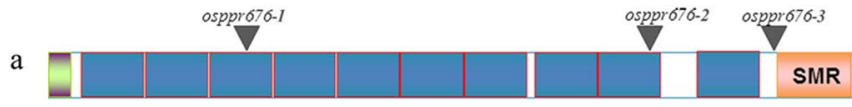

\section{Signal peptide $\quad$ PPR repeat}
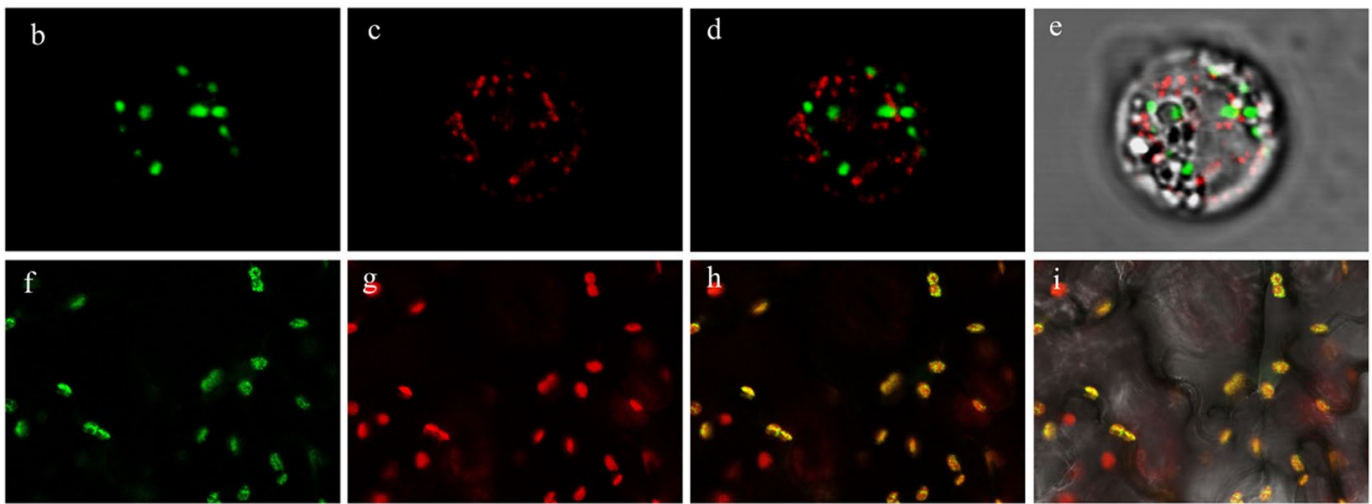

Figure 1. OsPPR676 is a plastid-localized PPR-SMR protein. (a) The OsPPR676 protein contains 10 PPR motifs and a SMR domain at the C-terminus. Locations of mutation sites for 3 studied alleles marked with triangles. (b) to (e) OsPPR676:GFP and a mitochondrial marker F1-ATPase- $\gamma$ :RFP co-transient expression in rice protoplast. (f) to (i) OsPPR676: GFP transient expression in tobacco epidermis cells. The tobacco leaf samples and protoplast were used to view GFP signals respectively. Fluorescence signals from OsPPR676-GFP (green) and F1-ATPase- $\gamma$ :RFP (red) were detected by confocal microscopy.

to restore rice fertility ${ }^{6}$. With the difference from RF5, RF6 works with OsHXK6 in mitochondria to stimulate the processing of transcript atp6-orfH79, leading to normal pollen development and fertility restoration ${ }^{7}$. Other $R f$ genes encoding PPR proteins include PPR592 in petunia (Petunia hybrida), $R f 1 k$ in Kosena rapeseed, $R f o$ in radish (Raphanus sativus), and PPR13 in sorghum (Sorghum bicolor) ${ }^{8-12}$.

All these Rf proteins are mitochondrial-targeted. In this study, we first report a plastid-localized PPR-SMR protein OsPPR676 required for both pollen development and plant growth in rice. As a small subgroup in the P-type PPR subfamily, PPR-SMR proteins are characterized by a PPR tract followed by a carboxy-terminal small MutS-related (SMR) domain ${ }^{13}$. All reported studies to date that investigated the function of PPR-SMR proteins have focused on Arabidopsis and maize. GUN1 is a central regulator of plastid retrograde signalling, where the developmental and functional state of the plastid controls the expression of nuclear gene-encoding plastid-localized proteins ${ }^{14}$. pTAC2 associates with the plastid-encoded RNA polymerase (PEP) and is required for its activity ${ }^{15}$, but the basis for this effect is unknown. The svr7 mutant in Arabidopsis was identified during a screen for suppressors of var2 variegation ${ }^{16}$. SVR7 is involved in the translational activation of the at $p B / E$ and $r b c L$ transcripts, resulting in a specific reduction in the accumulation of ATP synthase subunits $\mathrm{A}, \mathrm{B}, \mathrm{E}$, and $\mathrm{F}^{17}$. ATP4, the maize orthologue of SVR7, is also required for the translation of the atpB open reading frame (ORF) and for the accumulation of specific processed transcript isoforms from the atpF, $p s a J$ and $r p l 14$ loci $^{18}$. Other two PPR-SMR proteins, PPR53 in maize, and SOT1, its orthologue in Arabidopsis, are required for maturation of the 23S-4.5 S rRNA dicistron and play essential roles in the biogenesis of the photosynthetic apparatus by promoting the expression of the chloroplast $n d h A$ and $r r n 23$ genes $^{19,20}$.

To further characterize the PPR-SMR protein subgroup and elucidate the function of the SMR domain, we characterized OsPPR676, the rice orthologue of ATP4 and SVR7. In the previous study of a basal transcription factor 3-like gene $O s j 10 g B T F 3^{21}$, OsPPR676 was identified as a candidate protein that interacts with Osj10gBTF3. Repression of Osj10gBTF3 caused significant plant miniaturization and pollen abortion ${ }^{21}$. In contrast to the mutant phenotypes of other plastid PPR-SMRs, which predominantly showed different levels of plant growth retardation and pale leaves ${ }^{14-16,18}$, osppr676 mutants showed not only growth retardation, but also pollen semisterility. The phenotype is similar with Osj10gBTF3 RNAi lines. Phenotypic analysis revealed that the SMR domain is not essential for OsPPR676 function. The results of anther RNA in situ hybridization indicated that OsPPR676 transcripts are principally expressed in the tapetum, and the total soluble lipids of osppr676 anthers were greatly reduced compared to the WT plants. Overall, this work characterized a rice PPR-SMR protein for the first time, and unravelled a probable new mechanism of male sterility in plants.

\section{Results}

OsPPR676 encodes a plastid-localized PPR-SMR protein. To study the function of OsPPR676, we analyzed OsPPR676 sequence, indicating that the OsPPR676 is the orthologue of maize ATP4 and Arabidopsis SVR7. Motif prediction by the algorithm TPRpred (http://tprpred.tuebingen.mpg.de/tprpred) showed that OsPPR676 contains 10 PPR motifs and has a C-terminal small MutS-related (SMR) domain, classifying this protein as a member of the PPR-SMR protein subgroup (Fig. 1a). 


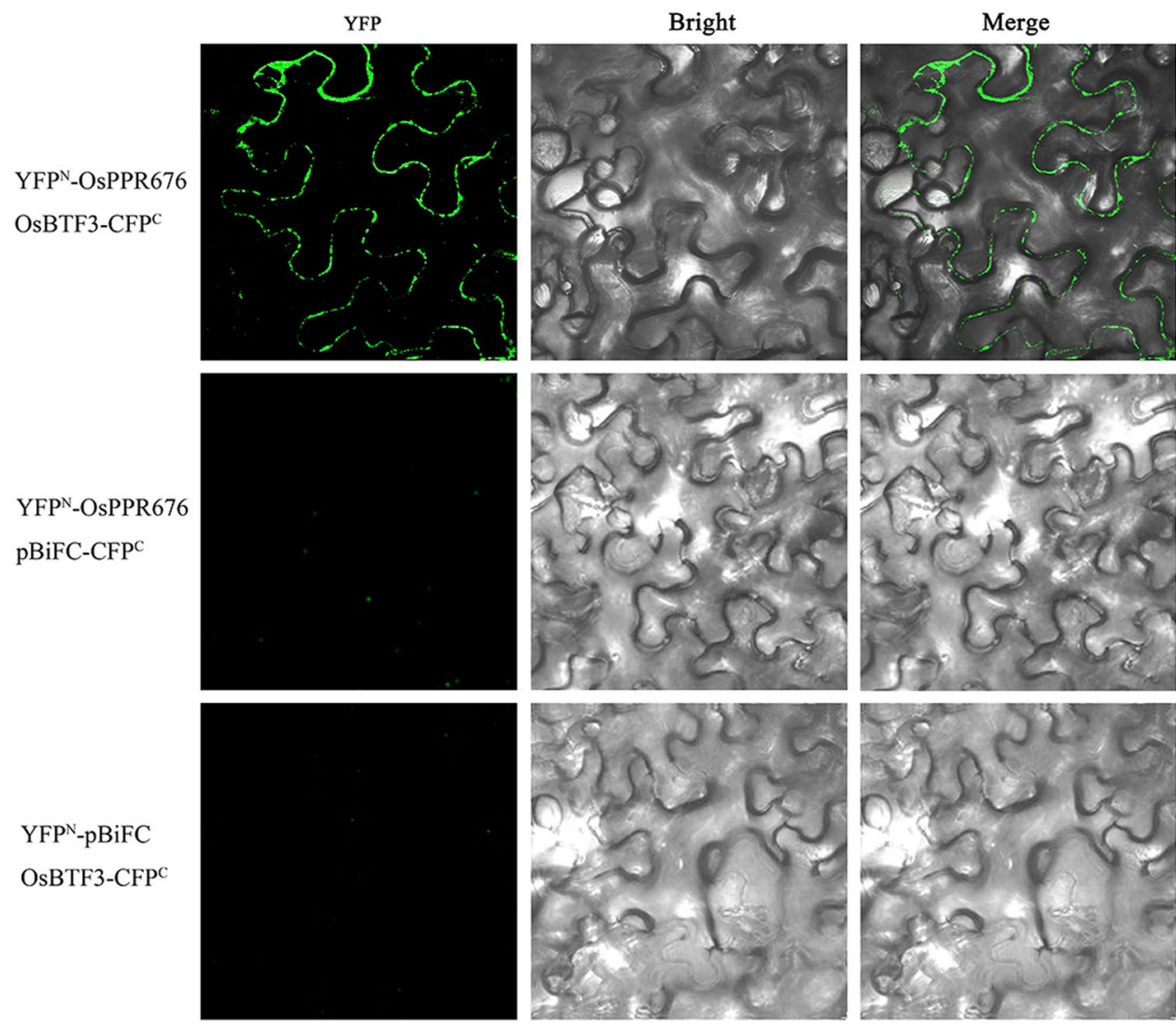

Figure 2. Bimolecular fluorescence complementation (BiFC) analysis of OsPPR676 and Osj10gBTF3. YFP OsPPR676, OsPPR676 fused with N-terminal of YFP; Osj10gBTF3 -CFPC, Osj10gBTF3 fused with C terminal of CFP. CFP ${ }^{\mathrm{C}}$ is modified from C-terminal of YFP in order to enhance fluorescence signal. As controls, combinations with the YFP ${ }^{\mathrm{N}}-\mathrm{O}$-PPR676 and the empty vector $\mathrm{pBiFC}-\mathrm{CFP} \mathrm{P}^{\mathrm{C}}$ or Osj10gBTF3 -CFPC and the empty vector $\mathrm{YFP}^{\mathrm{N}}$-pBiFC were included.

To experimentally determine the subcellular localization of OsPPR676, we fused full-length OsPPR676 with green fluorescent protein (GFP) and transiently expressed the construct in tobacco epidermis cells. Confocal laser scanning microscopy analysis of the transformed tobacco cells showed co-localization of the GFP signal of OsPPR676-GFP with the chlorophyll autofluorescence in the plastids (Fig. 1h). Previously, F1-ATPase- $\gamma$ : RFP was shown to target to the mitochondria ${ }^{22}$. The OsPPR676-GFP construct and the mitochondrial marker F1-ATPase- $\gamma$ : RFP were also transiently co-expressed in rice protoplasts, which showed that the GFP signal of OsPPR676-GFP was not localized to the mitochondria (Fig. 1d). Together, these results indicate that OsPPR676 encodes a plastid-localized PPR-SMR protein, as the conclusion made for its maize, Arabidopsis and radish orthologues previously ${ }^{16,18,23}$.

OsPPR676 interacts with Osj10gBTF3. To confirm the interaction between OsPPR676 and Osj10gBTF3, the full-length cDNAs of OsPPR676 and Osj10gBTF3 were cloned in binary pBiFC vectors containing the amino-terminal fragment of the eYFP fluorescent protein or carboxy-terminal fragment of the eCFP fluorescent protein $\left(\mathrm{eYFP}^{\mathrm{N}} \text { and } \mathrm{eCFP}^{\mathrm{C}} \text {, respectively }\right)^{24}$ to perform bimolecular fluorescence complementation $(\mathrm{BiFC})$ assays. All constructs were transformed into Agrobacterium tumefaciens. Different combinations of these constructs were mixed at an $\mathrm{OD}_{600}$ 1:1 ratio and injected into 2-3-week-old tobacco epidermal cells. Positive cytosol BiFC interaction signals between $\mathrm{YFP}^{\mathrm{N}}$-OsPPR676 and OsBTF3-CFPC ${ }^{\mathrm{C}}$ were detected with confocal fluorescence microscopy

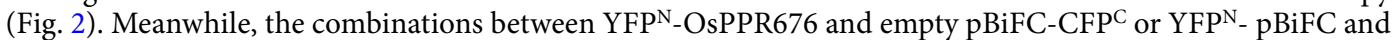
empty OsBTF3-CFP ${ }^{\mathrm{C}}$ were used as negative controls for the BiFC assay. None of these combinations showed green fluorescence signals in tobacco epidermal cells. These results suggest that OsPPR676 and Osj10gBTF3 directly interact in the cytosol and probably involve in the same regulatory pathway of pollen development.

Expression of OsPPR676. The expression of OsPPR676 was analyzed by qRT-PCR. The results indicated that the OsPPR676 transcripts were present in various vegetative and reproductive organs, including root, stem, leaf, sheath, anther, pistil, lemma, palea and seven different developmental stages of spikelet (Fig. 3a). Relatively high mRNA expression was observed in the leaf, sheath, lemma and palea, which all are green tissues rich in chloroplasts. Weak expression was detected in the root and anther, which are not green tissues or rich in plastids. Considering the fact that OsPPR676 is a plastid-localized protein, these results hence suggest that OsPPR676 may be expressed in all types of plastids, including the chloroplasts from green tissues and the leucoplasts and 

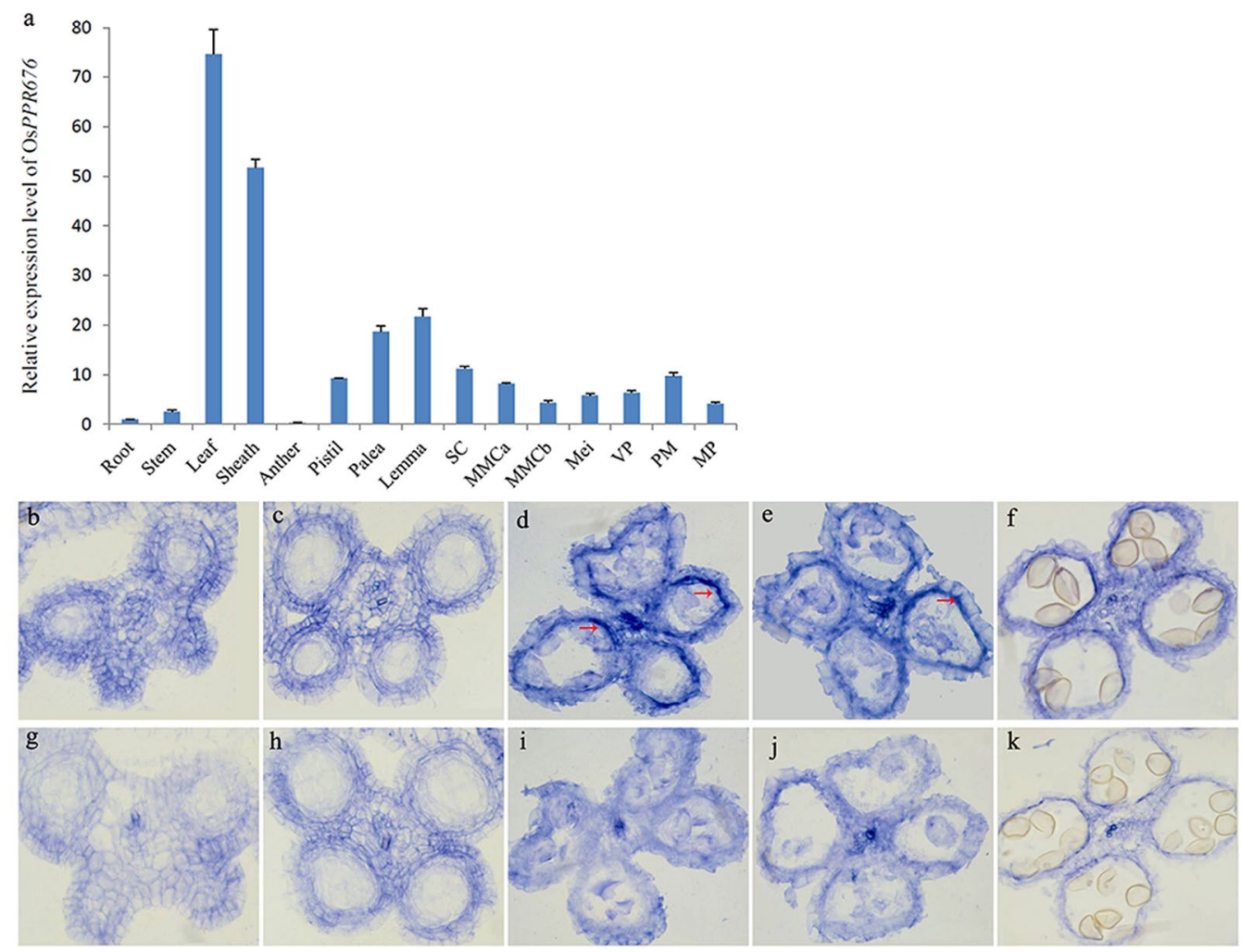

Figure 3. OsPPR676 expression pattern. (a) Expression analysis of OsPPR676 using qRT-PCR. RNA was extracted from spikelets of SC stage, MMC stage, Mei stage, VP stage, PM stage, MP stage, respectively. Error bars refer to SD of three biological repeats. (b) to (f) In situ hybridization assays of OsPPR676 in the anthers of the WT at SC stage (b), MMC stage (c), Mei stage (d), YM stage (e), and VP stage (f). (g) to (k) Negative controls with sense probe in anthers at SC stage $(\mathbf{g})$, MMC stage (h), Mei stage (i), YM stage (j), and VP stage (k). SC, sporogenous cell; MMC, microspore mother cell; Mei, meiosis; VP, vacuolated pollen; YM, young microspore; PM, pollen mitosis; MP, mature pollen.

chromoplasts from non-green tissues. In addition, the OsPPR676 function may not be limited to anther development. Rather, it may also have functions in other vegetative tissues during plant growth and development.

To more precisely determine the spatial and temporal patterns of OsPPR676 expression during anther development, we performed RNA in situ hybridization with WT floral sections. At the early sporogenous cell (SC) stage and the microspore mother cell (MMC) stage, no OsPPR676 expression was detected (Fig. 3b and c). Strong expression of OsPPR676 was detected in the tapetum cells in the meiosis (Mei) stage and young microspore (YM) stage anthers (Fig. 3d and e), but it was greatly reduced in the vacuolated pollen (VP) stage along with tapetum degradation (Fig. 3f). These results demonstrate that OsPPR676 is indeed expressed in the tapetum, which infers that it most likely acts directly on anther development.

osppr676 mutants generated by CRISPR/Cas9 system on a Nipponbare background. To further study the function of OsPPR676, we generated mutants by the CRISPR/cas9 system. We designed three different target sequences, SG638, SG640 and SG641 of OsPPR676 to construct sgRNA-CRISPR/Cas9 expression vectors. Each of these sgRNA-CRISPR/Cas9 constructs was transformed independently into rice calluses derived from mature seeds of Nipponbare. The obtained $\mathrm{T}_{0}$ plants were analyzed to detect mutations in the targeted sequence regions. Each target site had several similar mutant lines generated by different base mutations (Table S2). The total mutation rate for all three target sites reached $62.8 \%$ and homozygous mutants were found in the T0 plants of all three targets, accounting for approximately $20 \%$ of the plants examined (Table 1). All homozygous mutants segregated from T1 plants were shown in Table S2 (containing T0 homozygous plants), and the subsequent reliable phenotypic analysis and functional studies of protein motifs were carried out on the basis of these multiple diverse mutants.

Previous studies in mice and zebrafish indicated a low off-target effect of CRISPR/Cas9-induced mutagenesis ${ }^{25,26}$. Similarly in plants, deep sequencing of CRISPR/Cas-modified whole-genome did not detect any off-targets in Arabidopsis and detected only one off-target mutation case in rice $^{27,28}$. In our study, each sgRNA-CRISPR/Cas 9 construct (containing one specific target sequence) was transformed independently, resulting in multiple diverse homozygous mutants in each target site in $\mathrm{T}_{1}$ generation (shown in Table $\mathrm{S} 2$, including $\mathrm{T}_{0}$ homozygous). These homozygous mutants were used for phenotypic analysis and all lines mutated in the same target sequence shared the same phenotypes. 


\begin{tabular}{|c|c|c|c|c|c|c|}
\hline \multirow[b]{2}{*}{ Target } & \multirow[b]{2}{*}{ Guide RNA } & \multirow[b]{2}{*}{ No. of plants examined } & \multirow[b]{2}{*}{ No. of plants with mutations } & \multirow{2}{*}{$\begin{array}{l}\text { Mutation rate } \\
(\%)\end{array}$} & \multicolumn{2}{|c|}{ homozygous mutations } \\
\hline & & & & & Number & $\%$ \\
\hline SG638 & SgRNA1 & 21 & 11 & 52.4 & 3 & 14.3 \\
\hline SG640 & SgRNA2 & 18 & 13 & 72.2 & 4 & 22.2 \\
\hline SG641 & SgRNA3 & 31 & 20 & 64.5 & 7 & 22.6 \\
\hline total & & 70 & 44 & 62.8 & 14 & 20 \\
\hline
\end{tabular}

Table 1. Percentage of T0 plants found with OsPPR676 mutations in the target sequences.

In order to detect whether CRISPR/Cas9-mediated gene editing process produced any off-target event, we analyzed possible off-target sites corresponding to each target site predicted by software CRISPR-P (http://cbi. hzau.edu.cn/crispr/) via PCR product sequencing. The results reveal that there is definitely no any off-target mutation detected in these predicted off-target sites for all examined mutant lines (Table S3) as previous report ${ }^{27}$. Therefore, the possibility of off-target event for the CRISPR/Cas9-induced mutants of this study did not exist.

Phenotypic analysis of the CRISPR/Cas9-generated mutants and RNAi lines. All osppr676 mutants were created by the CRISPR/Cas9 system in Nipponbare background (osppr676-1, osppr676-2, osppr676-3 and similar lines). The truncated protein structures of osppr676-1, osppr676-2, osppr676-3 were shown in Fig. S2. All these mutant alleles displayed different levels of growth retardation and partial pollen sterile phenotypes. In the osppr676-1 allele, one base insertion in the 3rd PPR motif results in a frame shift and creates a stop codon in the $395^{\text {th }}$ amino acid (8th PPR motif). Osppr676-1 and all similar lines mutated in the same target sequence showed significant growth retardation, slightly pale green but viable seedlings (Fig. 4a), and partial sterile pollen phenotypes (Fig. 4g). In the osppr676-2 allele, a two-base deletion induces a frame shift, resulting in changes of amino acids in the 9th PPR motif, and creates a stop codon at the $483^{\text {th }}$ amino acid (10th PPR motif). This allele and similar lines showed a milder phenotype, but still significant growth retardation (Fig. 4b) and partial pollen sterility (Fig. 4h) compared with the WT. This partial pollen sterile phenotype of osppr676-1 and osppr676-2 is similar to previously reported $p s s 1$ and $o s h u b 1^{29,30}$. In the osppr676-3 allele, one base deletion results in a frame shift, and the translation is terminated by a stop codon in the $580^{\text {th }}$ amino acid. However, osppr676-3 and WT plants were phenotypically indistinguishable with regard to plant growth and pollen fertility (Fig. $4 \mathrm{c}$ and i). Compared with the WT, osppr676-1 and osppr676-2 had significantly shorter leaf and panicle, but no any change for osppr676-3 (Fig. $4 \mathrm{~d}$ and e). The different phenotypes are attributed to mutations in different motifs, the functions of which will be discussed later.

To further characterize the pollen differences between the WT and the osppr676-1 mutant, we examined the pollen grains using scanning electron microscopy. Mature WT pollen grains were plump, but only approximately half of the mutant pollen grains had a plump shape similar to the WT pollen, while the other half had a severe shrunken phenotype (Fig. 4k).

To more precisely determine the timing of the anther developmental defects in osppr676 mutants, we observed their anther sections at different developmental stages under light microscopy (Fig. 5 and Fig. S3). The WT anther sections were used as control. The results revealed that there were no significant differences between WT and osppr676-1 before the vacuolated pollen stage (Fig. 5). Once the anther developed to the vacuolated pollen stage, tapetal cells degenerated and produced abundant electron-dense Ubisch bodies. The microspores displayed vacuoles and had a round shape in WT anthers (Fig. 5d). However, in osppr676-1 anthers, only approximately half of the microspores had a normal round shape, similar to the WT, while the rest of the microspores were shrunken and irregularly shaped (Fig. 5h). These results are consistent with the pollen staining (Fig. 4g) and SEM data (Fig. 4k), indicating that osppr676-1 has partial pollen sterility. For osppr676-2 and osppr676-3, no significant differences were observed comparing with WT during all examined anther developmental stages (Fig. S3).

OsPPR676 RNAi and over-expression (OE) transgenic rice lines were also generated. As expected, the pollen fertility was declined in both RNAi line15 and 19, which resulted in reduction of their seed-setting rates from $84 \%$ of WT to $\sim 47 \%$ and $\sim 68 \%$, respectively (Fig. 6 ). However, the low seed-setting rate did not appear on the transgenic OE lines (Fig. 6; Table S4). Therefore, all above results consistently indicate that OsPPR676 determines the fertility of pollen in a large extent.

Translation of atpB mRNA is disrupted in the mutants. The question here is how does OsPPR676 determine the fertility of pollen in a large extent? It is known that atpB in the chloroplast encodes an important $\beta$-subunit of ATP synthase for production of ATP, which is essential for the synthesis of most cell organic components, including fatty acids. In maize, the PPR-SMR protein ATP4 is essential for the translation of this chloroplast atp $B^{18}$. To test whether the rice orthologue OsPPR676 has the similar function with the maize ATP4, we performed western blot analysis with an AtpB antibody to detect AtpB in WT and osppr676 mutants. The results revealed that the subunit AtpB production of the chloroplast ATP synthase was significant reduction in mutant osppr676-1 and osppr676-2 (Fig. 7a). A small quantity of AtpB production can be detected at low levels in the osppr676-2 line, in contrast with undetectable AtpB in the osppr676-1 line. This is in congruence with the results of ATP synthase activity(Fig. 7b) and the intermediate phenotype observed (Fig. 4). We also have already checked the RNA editing status of $a t p B$ and mRNA accumulation of the atpB, and we found that they all had no detectable alternation in osppr676 mutants (Fig. S4). These results thereby indicate that the rice pentatricopeptide repeat-SMR protein OsPPR676 similar to the maize orthologue ATP4 protein is also essential for the translation of rice chloroplast atpB subunit. 


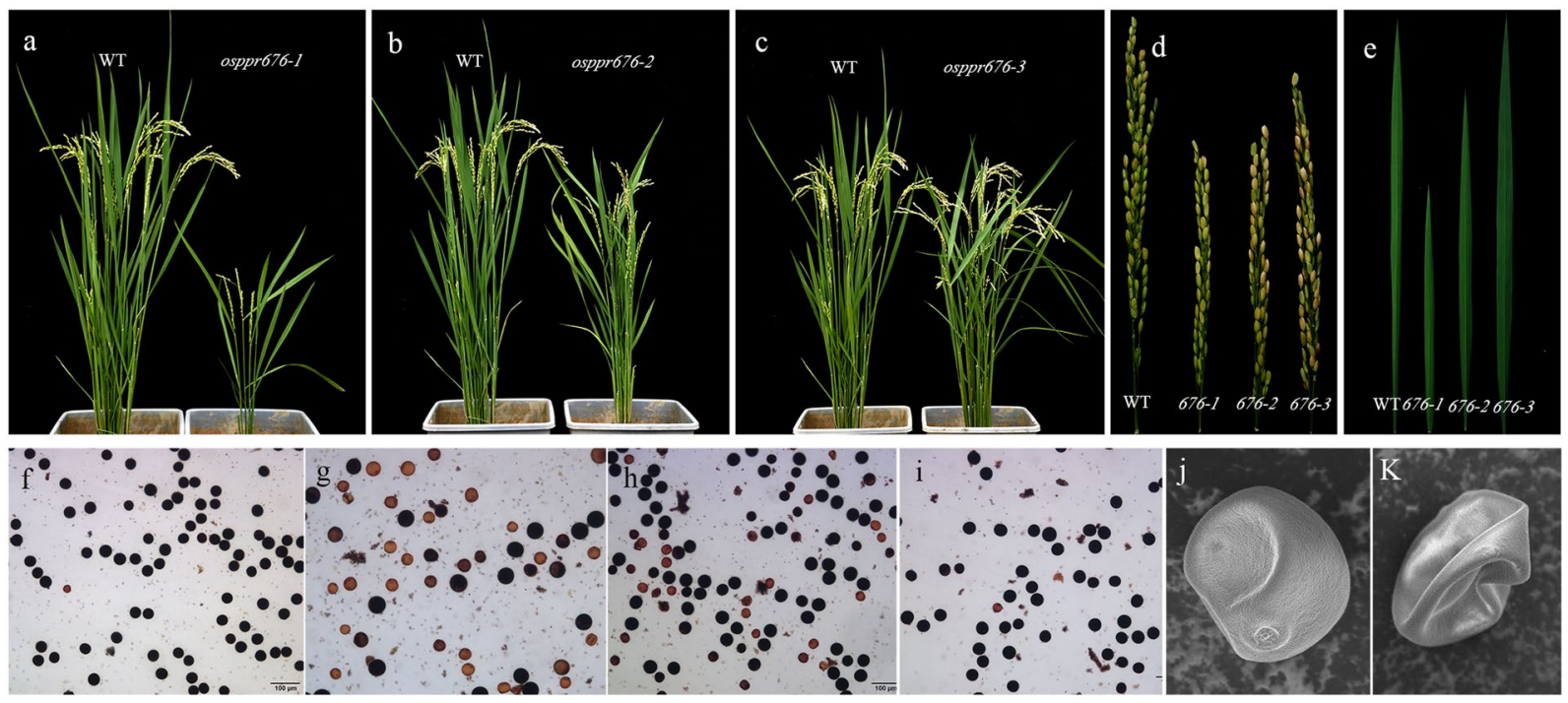

Figure 4. Phenotypes of the osppr676 alleles. (a,b) and (c) Phenotype comparison of the WT, osppr676-1, osppr676-2 and osppr676-3 mutant plants. (d) and (e) Panicle length and leaf length comparison of the WT, osppr676-1, osppr676-2 and osppr676-3 mutants. (f), (g), (h), and (i) Pollen grain from the WT (f), osppr676-1 (g), osppr676-2 (h), and osppr676-3 (i) respectively, stained with iodine potassium iodide solution. Bars $=100$ um. (j) and (k) A higher magnification SEM image of a single pollen grain from WT (j) and osppr676-1 (k), respectively.
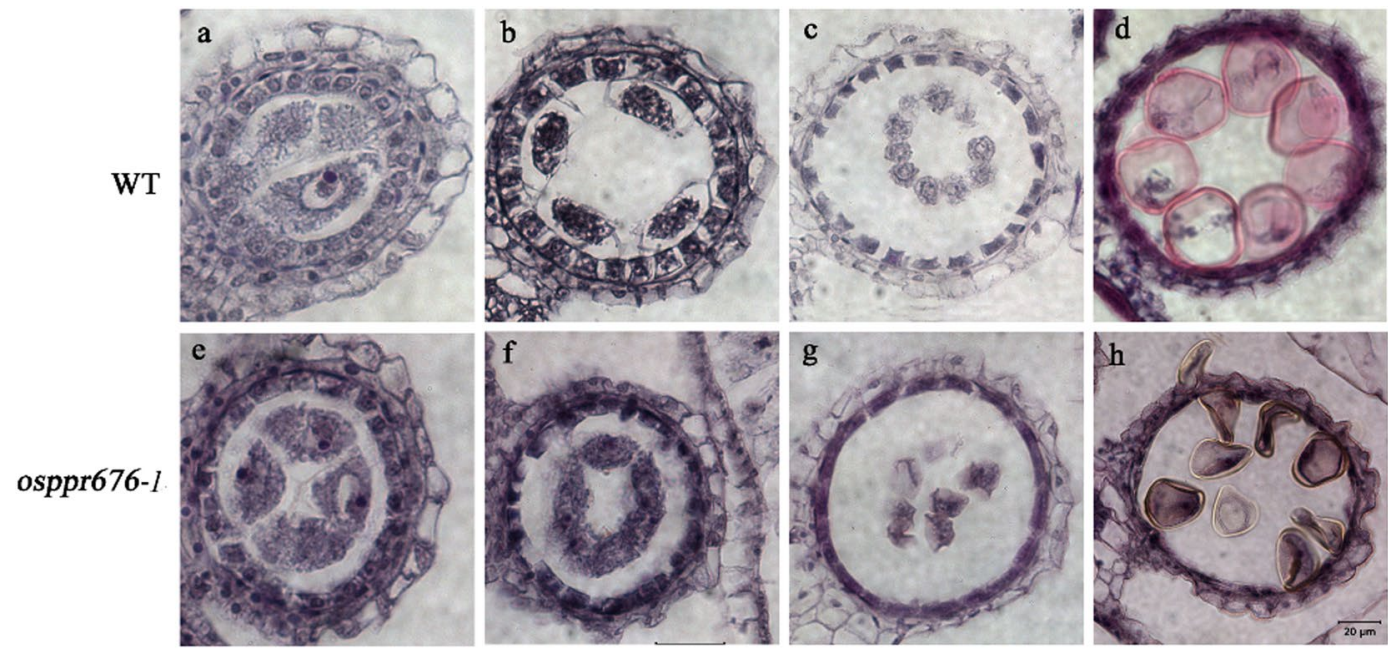

Figure 5. Comparison of cross sections of anthers from WT and osppr676-1 mutants. The WT anther is shown in $(\mathbf{a}, \mathbf{b}, \mathbf{c})$, and $(\mathbf{d})$ and the osppr676-1 mutant anther in (e,f,g), and (h). (a) and (e) The MMC (microspore mother cell) stage. (b) and (f) The late meiosis stage. (c) and (g) The young microspore stage. (d) and (h) The vacuolated pollen stage. Bars $=20 \mathrm{um}$.

ATP synthase activity is significantly declined in the leaf tissue of the osppr676 mutants. Considering the fact that the AtpB is a subunit of the ATP synthase, reducing or losing the production of this subunit will most likely affect the activity of the holoenzyme. To test this hypothesis, we assayed ATP synthase activity in WT and osppr676 mutants. The results indicated that the ATP synthase activity in all detected lines was gradually declined during the assay (Fig. 7b). osppr676-1 and osppr676-2 mutants all show lower activity than WT at different degrees and time points. For instance, ATP synthase activity of osppr676-1, who has the most serious phenotype with the single base insertion mutation in the $3^{\text {rd }} \mathrm{PPR}$, is almost three folds lower than that of $\mathrm{WT}$ at $30 \mathrm{sec}$ (Fig. 7b). Furthermore, during the whole process of reaction time extended from 0.5 to $11 \mathrm{~min}$, this reduction is still kept (Fig. 7b). These results hence confirm that the OsPPR676 is really essential for the synthesis of rice AtpB subunit and thus the activity of ATP synthase.

Generation of fatty acids and starch is altered in anther and pollen of osppr676 mutants. Fatty acids and starch are two important components required for normal plant growth and pollen development ${ }^{31}$, which 

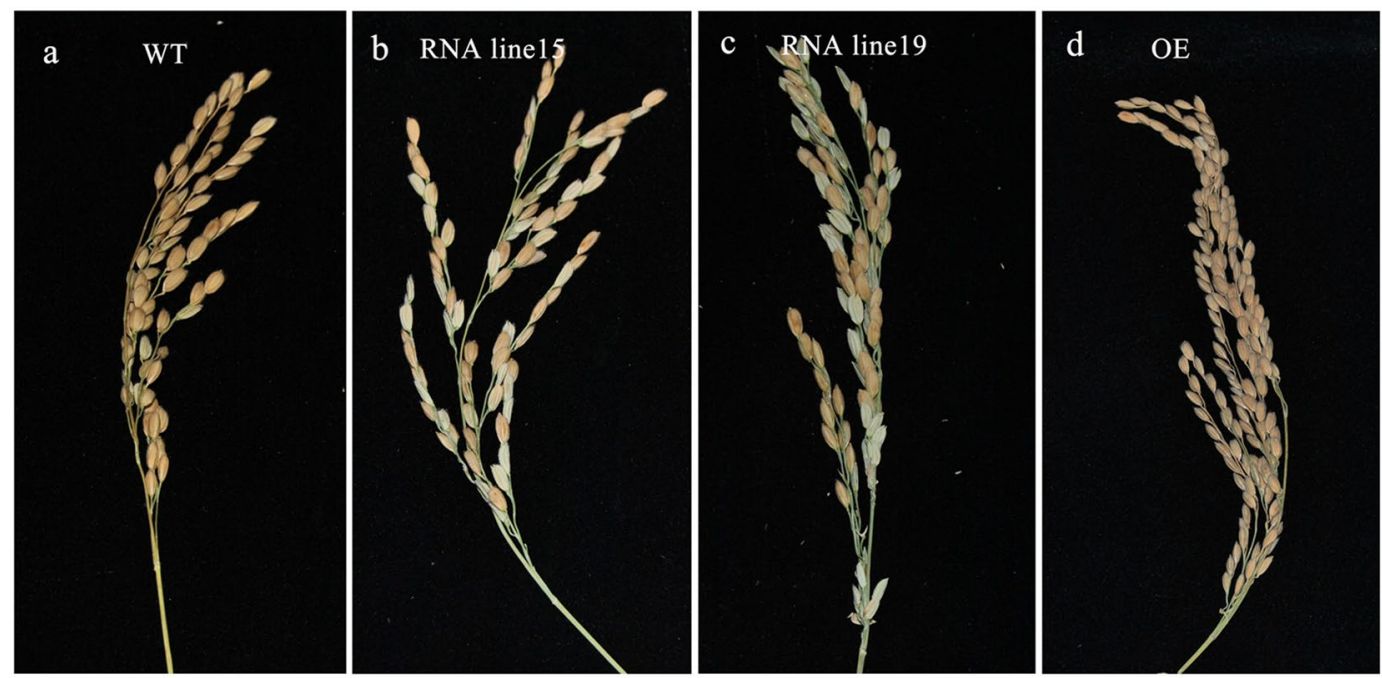

Figure 6. Phenotypes of the transgenic OsPPR676 RNAi and over expression lines. (a) to (d) Comparison of WT panicle (a), OsPPR676 RNAi line15 (b) and line19 panicle (c), and OsPPR676 over expression line (d) at the harvest stage.
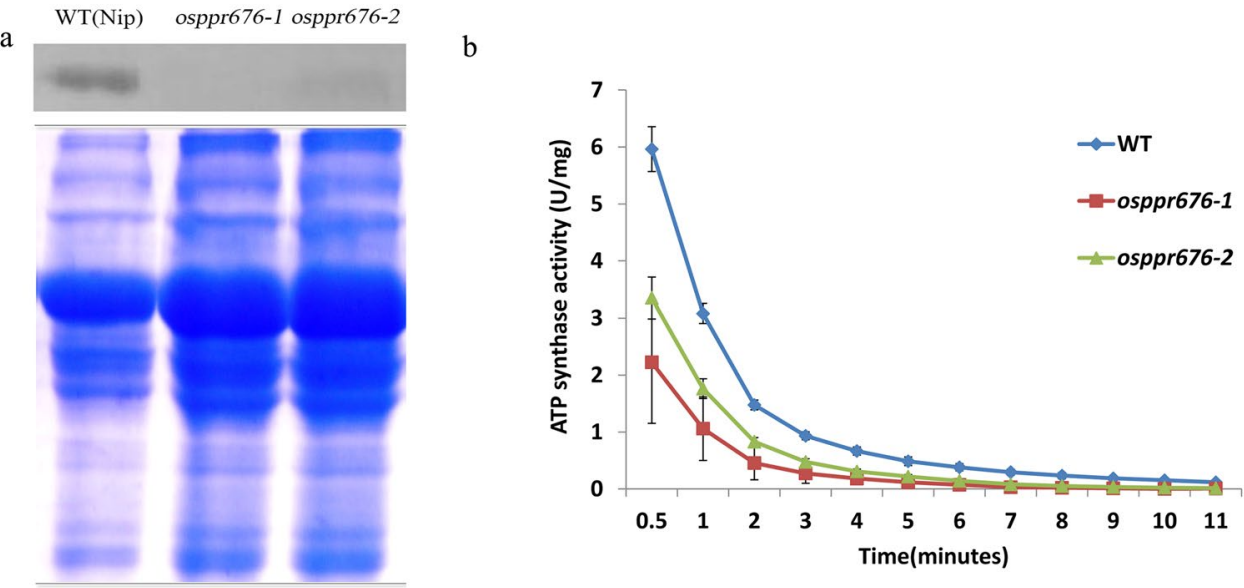

Figure 7. Absence of AtpB subunit production and reduction of ATP synthase activity in rice osppr676 mutants. (a) Western blot analysis with AtpB antibody on total proteins from the osppr676-1 and osppr676-2 mutants and WT seedlings (Up panel) and Coomassie Blue staining of the loading amount of samples (Down panel). Full-length gel and blot with original contrast are displayed in Fig. S6. (b) ATP synthase activity measured in the WT, osppr676-1 and osppr676-2.

synthesized in the plastids in an ATP-dependent process ${ }^{31-33}$. To determine whether generation of the fatty acid components was altered in the osppr676 mutants, we analysed the composition of total soluble lipids from WT and osppr676 anthers using gas chromatography-mass spectrometry (GC-MS) and gas chromatography-flame ionization detection (GC-FID) ${ }^{34}$. The results showed that the total soluble lipids in osppr676-1 and osppr676-2 anthers were greatly reduced compared to WT. We detected a concentration of $22.377 \mu \mathrm{g} / \mathrm{mg}$ soluble fatty acids in WT anthers but only $9.541 \mu \mathrm{g} / \mathrm{mg}$ and $13.057 \mu \mathrm{g} / \mathrm{mg}$ in osppr676-1 and osppr676-2 (Table S5), respectively, which corresponds to a $57.36 \%$ and $41.65 \%$ reduction, respectively, compared to WT (Fig. 8a). Although the major fatty acid components were still detected in mutant anthers, almost all components from $\mathrm{C} 12$ acid to C26 acid were significantly reduced (Fig. 8b). A detailed description of the altered fatty acid components is shown in Table S5. The altered synthesis of starch component can be seen from Fig. 4g,h, which have $20 \%$ to $45 \%$ of the iodine-stained pollen grains filling with no or very little starch. All above results suggest that OsPPR676 involves in the biosynthesis of both fatty acids and starch, which are important components required for normal plant growth and pollen development.

\section{Discussion}

The plastid-localized OsPPR676 is essential for plant growth and pollen development in rice. OsPPR676 is the ortholog of ATP4 and SVR7 and has a similar function for production of AtpB subunit (Fig. 7), but the phenotypic expression of these three genes after mutation is partially different. The atp 4 , which was 
a

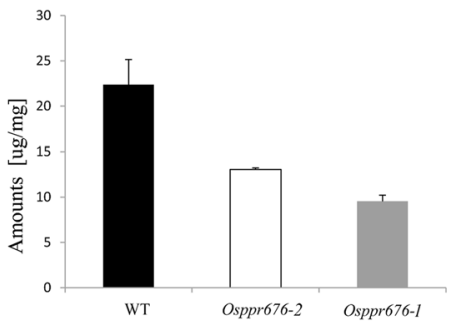

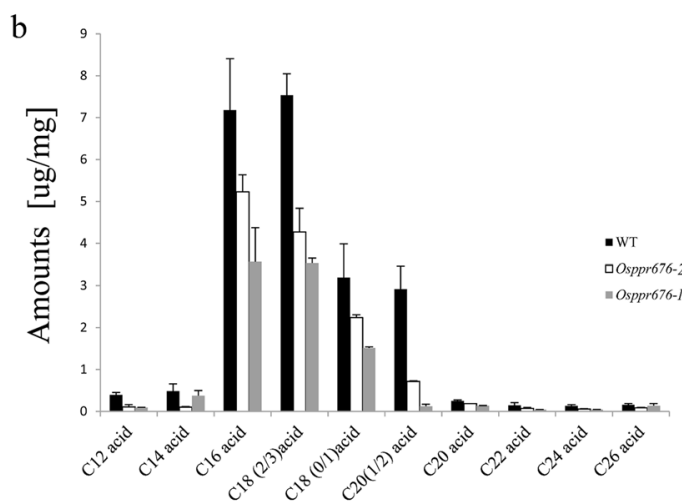

Figure 8. Analysis of anther soluble lipids in the WT, osppr676-1, and osppr676-2. (a) Total soluble lipids amount per mg dry weight anther in the WT (black bars) and osppr676-1 (gray bars) and osppr676-2 (white bars). Error bars indicate SD $(\mathrm{n}=5)$. (b) Soluble lipids constituents, amount per mg dry weight anther in the WT (black bars) and osppr676-1 (gray bars) and osppr676-2 (white bars). Error bars indicate SD $(\mathrm{n}=5)$. Compound names are abbreviated as follows: $\mathrm{C} 12$ acid, lauric acid; $\mathrm{C} 14$ acid, tetradecanoic acid; C16 acid, hexadecanoic acid; C18 (0/1)) acid, octadecanoic acid and oleic acid; C18 (2/3) acid, linoleic acid and linolenic acid; C20 acids, Eicosanoic acid; C20 (1/2) acid, paullinic acid and eicosadienoic acid; C22 acid, docosanoic acid; C24 acid: tetracosanoic acid; C26 acid, hexacosanoic acid. All acids were analyzed as methyl esters.

screened from the collection of nonphotosynthetic maize mutant, exhibits pale-green phenotypes and the homozygous dies after three weeks of growth on soil ${ }^{18}$. The mutations of $S V R 7$ account only for slightly pale green and developmentally retarded but viable and fertile plants ${ }^{17,35}$. By contrast, the CRISPR/cas9-induced mutants osppr676-1 and osppr676-2 created in this study display viable, developmentally retarded and partially sterile plants (Figs 4 and 5h). These phenotypic variations were attributed to the differences in the accumulation of ATP synthase subunits as suggested by Zoschkel et al. (2013) previously. As long as accumulation of one or more ATP synthase subunits is reduced, the activity of ATP synthase and ATP yield will be depressed. This will affect ATPdependent biosynthesis of fatty acids, carbohydrates, and other organic matters, finally impacting on plant growth and pollen development. Following such a consideration, we measured ATP synthase activity of WT and osppr676 mutants. The data revealed it was indeed remarkably reduced in two severe mutants osppr676-1 and osppr676-2 (Fig. 7b). We further analyzed composition of total soluble lipids in the anthers of these osppr676 mutants. The results, as expected, confirmed the great reduction of total soluble lipids in osppr676-1 and osppr676-2 as compared with that in WT (Fig. 8). In addition, the retarded growth of the plants (Fig. 4a,b) and appearance of the sterile pollens with faint iodine-staining (Fig. 4g,h) also indicates the significant reduction of the total dry matter including carbohydrates, proteins, and lipids that were synthesized in these mutant plants.

Lipids play crucial roles in successful pollen development ${ }^{31}$. Fatty acids and carotenoids are the major components of pollen coat, which are deposited from outside of the pollen, as they are synthesized and secreted by the tapetum $^{36}$. By far, several genes involved in synthesis and transport of these tapetal lipids have been confirmed essential for pollen fertility, such as Wax-deficient anther $1(W D A 1)^{37}$, Defective pollen wall $(D P W)^{38}, C Y P 704 B 2^{39}$, and $\mathrm{Faxl}^{40}$. Furthermore, polar lipids involve in the form of densely packed membranes, and neutral lipids such as triacylglycerols (TAG) involve in the form of lipid droplets ${ }^{41,42}$. Starch also accumulates as internal substances of pollen during development. Mutation of the genes that are responsible for the synthesis and transport of these internal lipids and carbohydrates also results in defects of male reproduction, such as mutant gpat $9^{43}$, iput $t^{44}$, $h m g 2^{45}, s m t 2^{46}, c s a^{47}$, and $m i a^{48}$. Datta et al. ${ }^{32}$ found that two proteins, hexose transporter and plasma membrane $\mathrm{H}$-ATPase, involving in starch biosynthesis, altered patterns of expression during pollen maturation process and determined pollen sterility. All these reports provide the supporting evidences that OsPPR676 plays crucial role in the ATP-dependent biosynthesis of organic matter such as lipids, proteins, and carbohydrates via regulating production of AtpB subunit of ATP synthase, thus affecting plant growth and pollen development in rice.

The SMR domain is not essential and PPR motifs are important for OsPPR676 protein function. To study the functions of the OsPPR676 motifs, we designed three different target sequences of the CRISPR/Cas9 mutation system, resulting in different mutant lines with a disruption in different regions of the $3^{\prime}$-domain of OsPPR676. In the osppr676-3 allele, the mutation produces a truncated OsPPR676 protein with a disrupted SMR domain (Fig. S2). Several PPR-SMR proteins have been analysed experimentally thus far ${ }^{15,17-20,49}$, but the function of the SMR domain in PPR proteins is still unknown. In this study, osppr676-3 and WT plants were phenotypically indistinguishable with regard to plant growth and pollen fertility (Fig. 4c,i), which indicates that the SMR domain is not essential for OsPPR676 function. The SMR domain was originally identified as the C-terminal region of bacterial MutS2 proteins ${ }^{19}$. Although the SMR domain is believed to function in transcription and to have DNA-binding activity, there is little experimental data on its contribution to PPR-SMR function. In higher plants, PPR-SMRs are a very small subgroup of PPR proteins, with only 8 members in Arabidopsis ${ }^{13}$. Most reported molecular functions of the SMR domain are from bacteria and mammals ${ }^{50-53}$. The only exception is GUN1 from Arabidopsis, but all gun1 mutants showed wild type-like phenotypes under normal growth 
conditions ${ }^{54}$. Although the present findings provide a foundation for hypotheses concerning the functions of the SMR domain in PPR-SMR proteins, an alternative possibility is that, as an ancient domain, the function of the SMR domain has been degraded in plant PPR-SMRs during evolution.

The last two PPR motifs and the SMR domain are destroyed in the osppr676-2 allele mutant (Fig. S2). Phenotypic analysis indicated that the osppr676-2 mutants showed a milder phenotype than osppr676-1, but still significant growth retardation (Fig. 4b) and partial pollen sterility (Fig. 4h) compared with the WT. These results indicated that the last two PPR motifs are important for OsPPR676 function. The truncated version of OsPPR676 may also be produced in the osppr676-1 mutant, which has an amino acid change from 3rd PPR motif, and the last three PPR motifs and the SMR domain are completely lost (Fig. S2). The osppr676-1 mutant has a much more serious defective phenotype, showing very weak growth with shorter and fewer spikelets than WT plants, and its pollen sterility is also more severe than osppr676-2 (Fig. 4a and g). These results indicate that the major functions of OsPPR676 are destroyed in osppr676-1, and the third to eighth PPR motifs play essential roles in OsPPR676 function.

Therefore, the SMR domain of OsPPR676 is not critical for the function in the Nipponbare background, but PPR motifs can not be destroyed for normal protein functions. In addition, different target sequences can be selected according to the purposes of the study using the CRISPR/Cas9 mutation system to generate multiple mutants (Table S2). Reliable phenotypic analysis and functional studies of motifs could be supported by many diverse mutants. Thus, the CRISPR/Cas9 mutation system is a useful tool to study the role of different protein motifs.

OsPPR676 and Osj10gBTF3 are likely involved in the same male reproduction regulation pathway. In our previous study, the candidate protein OsPPR676 was shown to interact with Osj10gBTF $3^{21}$. The interaction of these two proteins was confirmed by bimolecular fluorescence complementation (BiFC) assays in this study (Fig. 2). BTF3 encodes the $\beta$-subunit of the nascent polypeptide-associated complex (NAC), which not only plays a role in the nucleus, influencing the transcription levels of some genes ${ }^{55-57}$, but is also involved in the targeting and translocation of nascent polypeptides ${ }^{58-60}$. Repression of Osj10gBTF3 causes significant plant miniaturization and pollen abortion ${ }^{21}$, which are similar to the phenotype of osppr676-1, although phenotype severity is different. Therefore, we hypothesize that Osj10gBTF3 probably participates in OsPPR676 transportation to the plastids. Although Osj10gBTF3 and OsPPR676 are not localized in the same organelle, they most probably interact in the cytoplasm during the transportation of OsPPR676 from cytoplasm, where it is produced, to plastids. Consequently, OsPPR676 and Osj10gBTF3 may be involved in the same male reproduction regulatory pathway. Further studies are still needed to confirm this hypothesis.

\section{Materials and Methods}

Plant materials and growth conditions. The osppr676 mutants were generated by the CRISPR/Cas9 mutation system on the Nipponbare background (Oryza sativa L. ssp. japonica). The sgRNA-CRISPR/Cas9 plant expression vectors were constructed (Fig. S1), and rice transformation was performed as previously described ${ }^{61}$. PCR was carried out to amplify the genomic regions surrounding the CRISPR target sites using specific primers (Table S1) to confirm the mutants. The confirmed $\mathrm{T}_{0}$ mutants were initially cultivated in the growth chamber and then transplanted into paddy field to grow to mature.

Pollen fertility examination. To analyse pollen viability, pollen sampled from the spikelets of the WT and mutant plants just before flowering was stained with $1 \%(\mathrm{w} / \mathrm{v})$ iodine and potassium iodide $\left(\mathrm{I}_{2}-\mathrm{KI}\right)$ solution $^{62}$. Three biological replicates were used. The stained pollen grains were visualized, and images were recorded using a Leica DMIRB fluorescence microscope.

Generation of OsPPR676 over-expression and RNAi lines. To construct the over-expression vector, the OsPPR676 cDNA fragment was PCR amplified with primers OsPPR676-OE-F and OsPPR676-OE-R (Table S1), and ligated into the binary vector pCAMBIA1300 to produce the over-expression construct $P C A M$ BIA1300-35S::OsPPR676::NOS. For the RNAi vector construction, the PCR products amplified from cDNA using the primers OsPPR676-KpnI and OsPPR676-BamHI, OsPPR676-SpeI and OsPPR676-SacI (Table S1) were digested with two pairs of restriction enzymes: KpnI/BamHI and SpeI/SacI, respectively. The different digested fragments were then ligated into the binary vector pTCK303. Both vectors were introduced into the wild-type cultivar Nipponbare using Agrobacterium-mediated transformation. Transformation was performed as previously described ${ }^{61}$.

Scanning electron microscopy analysis. Fresh WT (Nipponbare) and osppr676-1 mutant pollen grains were air dried for approximately 30 minutes before viewing on a Hitachi S-4700 scanning electron microscope at an accelerating voltage of $5 \mathrm{kV}$.

Light microscopy of cytological sections. The developing stages of anthers were classified according to spikelet length and anther morphology ${ }^{63}$, and anthers, leave and stems were then collected and fixed in a solution containing 50\% ethanol, 5\% glacial acetic acid, and $3.7 \%$ formaldehyde for $24 \mathrm{~h}$ at $4{ }^{\circ} \mathrm{C}$ and were dehydrated using an ethanol series $(50 \%, 70 \%, 85 \%, 95 \%$, and $100 \%$ ethanol). After clearing with xylene and paraffin wax infiltration, the sample was embedded and sectioned at 6 to $10 \mu \mathrm{m}$ thickness under a Leica 2035 Biocut. The sections were stained with haematoxylin and $0.5 \%$ eosin for anthers or $0.5 \%$ toluidine blue for leave and stems. Images were captured using a Nikon Eclipse 80i microscope.

Analysis of anther total soluble lipids. Soluble lipids of the anthers were analysed as described previously $^{37-39}$. To extract soluble fatty acids, $10 \mathrm{mg}$ of freeze-dried anther materials were extracted with $1 \mathrm{~mL}$ of 
chloroform/methanol $(1: 1[\mathrm{v} / \mathrm{v}])$. They were first incubated at $50^{\circ} \mathrm{C}$ for $30 \mathrm{~min}$ and then overnight with constant shaking at room temperature. This extraction was repeated three times to ensure that no soluble lipids were left in the anther samples. The combined lipid extracts were then evaporated under a gentle stream of nitrogen gas until they reached a final volume of $100 \mu \mathrm{L}$. All soluble lipid samples were transesterified in $1 \mathrm{~mL}$ of $1 \mathrm{~N}$ methanolic $\mathrm{HCl}$ for $2 \mathrm{~h}$ at $80^{\circ} \mathrm{C}$. After the addition of $2 \mathrm{~mL}$ of saturated $\mathrm{NaCl} /$ water and $20 \mu \mathrm{g}$ of dotriacontane (Fluka) as an internal standard, the transesterified soluble lipids were subsequently extracted three times with $1 \mathrm{~mL}$ of hexane. The organic phases were combined, the solvent evaporated, and the remaining sample derivatized as described above. GC-MS and GC-FID analyses were performed as described by Franke et al. ${ }^{34}$. The results of soluble lipid analysis were related to dry weights of the anthers.

Subcellular localization of the OsPPR676 protein. To generate a translational protein fusion between the OsPPR676 signal peptide and GFP, full-length OsPPR676 was amplified by PCR from WT rice (Nipponbare) and cloned into pENTR/D-TOPO (Invitrogen, USA). The fusion was introduced into the binary vector pGWB5 (a gift from Tsuyoshi Nakagawa, Shimane University) by GATEWAY site-specific recombination (Invitrogen). The binary construct contains a cauliflower mosaic virus $35 \mathrm{~S}$ promoter that allows constitutive expression of the full-length OsPPR676: GFP fusion. Then, these constructs were transformed into Agrobacterium tumefaciens strain EHA105. Using established protocols ${ }^{64}$, the EHA105 strain harbouring the OsPPR676: GFP fusion expression plasmid was infiltrated into Nicotiana tabacum leaves to transiently express the fusion protein.

In addition, rice protoplasts were isolated from etiolated stems of 9-day-old Zhong Hua 11 grown at $28^{\circ} \mathrm{C}$ in a dark chamber. The pGWB5-OsPPR676: GFP plasmid and the mitochondrial marker F1-ATPase- $\gamma: R F P$ were co-transformed into rice protoplasts by polyethylene glycol-mediated transformation as previously described ${ }^{65}$. The infiltrated Nicotiana tabacum leaves and rice protoplasts were used for GFP and MitoTracker red signal detection by an Olympus FluoView FV1000 confocal microscope.

RNA in situ hybridization. To generate gene-specific and control sense RNA probes, we amplified the gene-specific region of the OsPPR676 cDNA fragment using primers listed in Table S1, which was then cloned into the pGEM-T vector (Promega). The clone was digested with SalI and transcribed in vitro under the T7 and SP6 promoters by RNA polymerase using a DIG RNA labelling kit (Roche). In situ hybridization was performed as previously described ${ }^{66,67}$.

qRT-PCR analysis. Total RNA was isolated using TRIzol reagent from rice tissues, including the root, stem, leaf, sheath, anther, pistil, palea, lemma, and anther at different stages according to spikelet length and anther morphology ${ }^{63}$. Approximately $1 \mu \mathrm{g}$ of RNA per sample was treated by genomic DNA eraser (TaKaRa) and then used to synthesize cDNA with the PrimeScript RT reagent kit. Two microlitres of cDNA was used as a template for RT-PCR. All the primers for RT-PCR are listed in Table S1. Real-time quantitative PCR was performed with a LightCycler 480 (Roche). Amplification was conducted using the following protocol: $95^{\circ} \mathrm{C}$ for $30 \mathrm{~s}, 40$ cycles of $95^{\circ} \mathrm{C}$ for $5 \mathrm{~s}$, and $60^{\circ} \mathrm{C}$ for $30 \mathrm{~s}$. ACTIN was used as an internal control. Each experiment was repeated three times, each with three replicates.

Bimolecular fluorescence complementation assays. By applying Gateway technology, the full-length cDNAs of OsPPR676 and Osj10gBTF3 were cloned in binary pBiFC vectors containing the amino-terminal fragment of the eYFP fluorescent protein or carboxy-terminal fragment of the eCFP fluorescent protein (eYFP ${ }^{\mathrm{N}}$ and $\mathrm{eCFP}^{\mathrm{C}}$, respectively $)^{24}$. $\mathrm{CFP}^{\mathrm{C}}$ is modified from $\mathrm{YFP}^{\mathrm{C}}$ to enhance the fluorescence signal in BiFC assays. All constructs were transformed into EHA105. Different combinations of these constructs were mixed at a 1:1 $\mathrm{OD}_{600}$ ratio and injected into 3-4-week-old tobacco epidermal cells. After 36 hours, fluorescence signals were observed under a confocal fluorescence microscope.

Western-Blot Analysis. Total leaf proteins of wild-type, osppr676-1 and osppr676-2 plants were extracted as described previously ${ }^{68}$, and then subjected to SDS-PAGE on $12 \%$ gels. The quantification was confirmed by Coomassie Blue staining of the six different samples. For western-blot analysis, proteins on gels were electrophoretically transferred to a polyvinylidene difluoride membrane and blocked with a blocking buffer ( $3 \%$ bovine serum albumin in phosphatebuffered saline [PBS] buffer [ $20 \mathrm{mM}$ Tris-Cl, $\mathrm{pH} 7.5$, and $150 \mathrm{mM} \mathrm{NaCl}]$ ). After washing with PBS buffer, the membrane was incubated with a polyclonalantibody against AtpB (1:2,000 dilution) in the blocking buffer for $10 \mathrm{~h} 4^{\circ} \mathrm{C}$. After washing with PBS buffer and then incubating for $1 \mathrm{~h}$ with goat anti-rabbit IgG-conjugated alkaline phosphatase (1:2,000 dilution). The antibody was obtained from Agrisera (AtpB).

Measurement of ATP synthase activity. The protein were prepared from $200 \mathrm{mg}$ fresh leaf sample and measured by continuous NADH-coupled enzyme assay kit (Genmed 50250.5, Shanghai, China). The measurement was typically performed at $28^{\circ} \mathrm{C}$ with $0.05 \mathrm{ml}$ sample protein in $0.95 \mathrm{ml}$ volume of the ATP synthase reaction buffer supplemented with a regeneration system ( $3 \mathrm{mM}$ PEP, $20 \mathrm{U} / \mathrm{ml} \mathrm{PK}), 20 \mathrm{U} / \mathrm{ml} \mathrm{LDH}$ and NADH. Absorbance data are collected at A340 using a SPECTRAmax 250 microplate spectrophotometer equipped with SOFTmax PRO software (Molecular Devices). Each line of WT and osppr676 mutants was measured with three biological replicates.

Data availability. Sequence data from this article for the cDNA and genomic DNA of OsPPR676 and Osj10gBTF3 can be found in the GenBank/EMBL/Gramene data libraries under accession numbers LOC_ Os03g1167 0 and LOC_Os10g34180 respectively. 


\section{References}

1. Gross, B. L. \& Zhao, Z. J. Archaeological and genetic insights into the origins of domesticated rice. Proc Natl Acad Sci USA 111, 6190-6197 (2014).

2. Cheng, S. H., Zhuang, J. Y., Fan, Y. Y., Du, J. H. \& Cao, L. Y. Progress in research and development on hybrid rice: a super-domesticate in China. Annals of botany 100, 959-966 (2007)

3. Wilson, Z. A. \& Zhang, D. B. From Arabidopsis to rice: pathways in pollen development. J Exp Bot 60, 1479-1492 (2009).

4. Hong, M. Molecular genetic analyses of microsporogenesis and micro grametogenesis in flowering plants. Annual Review of Plant Biology 56, 393-434 (2005).

5. Wang, Z. et al. Cytoplasmic male sterility of rice with boro II cytoplasm is caused by a cytotoxic peptide and is restored by two related PPR motif genes via distinct modes of mRNA silencing. The Plant cell 18, 676-687 (2006).

6. Hu, J. et al. The rice pentatricopeptide repeat protein RF5 restores fertility in Hong-Lian cytoplasmic male-sterile lines via a complex with the glycine-rich protein GRP162. The Plant cell 24, 109-122 (2012).

7. Huang, W. et al. Pentatricopeptide-repeat family protein RF6 functions with hexokinase 6 to rescue rice cytoplasmic male sterility. Proc Natl Acad Sci USA 112, 14984-14989 (2015).

8. Brown, G. G. et al. The radish Rfo restorer gene of Ogura cytoplasmic male sterility encodes a protein with multiple pentatricopeptide repeats. Plant J 35, 262-272 (2003).

9. Bentolila, S., Alfonso, A. A. \& Hanson, M. R. A pentatricopeptide repeat-containing gene restores fertility to cytoplasmic malesterile plants. Proc Natl Acad Sci USA 99, 10887-10892 (2002).

10. Desloire, S. et al. Identification of the fertility restoration locus, Rfo, in radish, as a member of the pentatricopeptide-repeat protein family. EMBO reports 4, 588-594 (2003).

11. Koizuka, N. et al. Genetic characterization of a pentatricopeptide repeat protein gene, orf687, that restores fertility in the cytoplasmic male-sterile Kosena radish. Plant J 34, 407-415 (2003).

12. Klein, R. R. et al. Fertility restorer locus Rf1 of sorghum (Sorghum bicolor L.) encodes a pentatricopeptide repeat protein not present in the colinear region of rice chromosome 12. Theor Appl Genet 111, 994-1012 (2005).

13. Liu, S., Melonek, J., Boykin, L. M., Small, I. \& Howell, K. A. PPR-SMRs: Ancient proteins with enigmatic functions. RNA Biol 10, 1501-1510 (2013).

14. Koussevitzky, S. et al. Signals from chloroplasts converge to regulate nuclear gene expression. Science 316, 715-719 (2007).

15. Pfalz, J., Liere, K., Kandlbinder, A., Dietz, K. J. \& Oelmuller, R. pTAC2, -6, and -12 are components of the transcriptionally active plastid chromosome that are required for plastid gene expression. The Plant Cell 18, 176-197 (2006).

16. Liu, X., Yu, F. \& Rodermel, S. An Arabidopsis pentatricopeptide repeat protein, SUPPRESSOR OF VARIEGATION7, is required for FtsH-mediated chloroplast biogenesis. Plant physiology 154, 1588-1601 (2010).

17. Zoschke, R., Qu, Y., Zubo, Y. O., Borner, T. \& Schmitz-Linneweber, C. Mutation of the pentatricopeptide repeat-SMR protein SVR7 impairs accumulation and translation of chloroplast ATP synthase subunits in Arabidopsis thaliana. J Plant Res 126, 403-414 (2013).

18. Zoschke, R. et al. The Pentatricopeptide Repeat-SMR Protein ATP4 promotes translation of the chloroplast atpB/E mRNA. Plant J 72, 547-558 (2012).

19. Zoschke, R., Watkins, K. P., Miranda, R. G. \& Barkan, A. The PPR-SMR protein PPR53 enhances the stability and translation of specific chloroplast RNAs in maize. Plant J 85, 594-606 (2016).

20. Wu, W. et al. SOT1, a pentatricopeptide repeat protein with a small MutS-related domain, is required for correct processing of plastid 23S-4.5S rRNA precursors in Arabidopsis thaliana. Plant J 85, 607-621 (2016).

21. Wang, Y. et al. Inhibition of a basal transcription factor 3-like gene Osj10gBTF3 in rice results in significant plant miniaturization and typical pollen abortion. Plant \& cell physiology 53, 2073-2089 (2012).

22. Jin, J. B. et al. The Arabidopsis dynamin-like proteins ADL1C and ADL1E play a critical role in mitochondrial morphogenesis. The Plant cell 15, 2357-2369 (2003).

23. Lahmy, S. et al. A chloroplastic RNA-binding protein is a new member of the PPR family. Febs Lett 480, 255-260 (2000).

24. Gampala, S. S. et al. An essential role for 14-3-3 proteins in brassinosteroid signal transduction in. Arabidopsis. Dev Cell 13, 177-189 (2007).

25. Yang, H. et al. One-step generation of mice carrying reporter and conditional alleles by CRISPR/Cas-mediated genome engineering. Cell 154, 1370-1379 (2013)

26. Hruscha, A. et al. Efficient CRISPR/Cas9 genome editing with low off-target effects in zebrafish. Development 140, 4982-4987 (2013).

27. Zhang, H. et al. The CRISPR/Cas9 system produces specific and homozygous targeted gene editing in rice in one generation. Plant Biotechnol J 12, 797-807 (2014).

28. Feng, Z. et al. Multigeneration analysis reveals the inheritance, specificity, and patterns of CRISPR/Cas-induced gene modifications in Arabidopsis. Proc Natl Acad Sci USA 111, 4632-4637 (2014).

29. Zhou, S. et al. Pollen semi-sterilityl encodes a kinesin-1-like protein important for male meiosis, anther dehiscence, and fertility in rice. The Plant Cell 23, 111-129 (2011).

30. Cao, H. et al. Histone H2B monoubiquitination mediated by HISTONE MONOUBIQUITINATION1 and HISTONE MONOUBIQUITINATION2 is involved in anther development by regulating tapetum degradation-related genes in rice. Plant physiology 168, 1389-1405 (2015).

31. Piffanelli, P., Ross, J. H. E. \& Murphy, D. J. Biogenesis and function of the lipidic structures of pollen grains. Sex Plant Reprod. 11, 65-80 (1998).

32. Datta, R., Chamusco, K. C. \& Chourey, P. S. Starch biosynthesis during pollen maturation is associated with altered patterns of gene expression in maize. Plant physiology 130, 1645-1656 (2002).

33. Martin, C. \& Smith, A. M. Starch Biosynthesis. The Plant Cell 7, 971-985 (1995).

34. Franke, R. et al. Apoplastic polyesters in Arabidopsis surface tissues-a typical suberin and a particular cutin. Phytochemistry 66, 2643-2658 (2005).

35. Liu, X. Y., Yu, F. \& Rodermel, S. An Arabidopsis pentatricopeptide repeat protein, SUPPRESSOR OF VARIEGATION7, is required for FtsH-mediated chloroplast biogenesis. Plant physiology 154, 1588-1601 (2010).

36. Ischebeck, T. Lipids in pollen - They are different. Biochimica et biophysica acta 1861, 1315-1328 (2016).

37. Jung, K. H. et al. Wax-deficient anther 1 is involved in cuticle and wax production in rice anther walls and is required for pollen development. The Plant Cell 18, 3015-3032 (2006).

38. Shi, J. et al. Defective pollen wall is required for anther and microspore development in rice and encodes a fatty acyl carrier protein reductase. The Plant cell 23, 2225-2246 (2011).

39. Li, H. et al. Cytochrome P450 family member CYP704B2 catalyzes the \{omega -hydroxylation of fatty acids and is required for anther cutin biosynthesis and pollen exine formation in rice. The Plant Cell 22, 173-190 (2010).

40. Li, N. et al. FAX1, a novel membrane protein mediating plastid fatty acid export. PLoS biology 13, e1002053 (2015).

41. Piffanelli, P., Ross, J. H. \& Murphy, D. J. Intra- and extracellular lipid composition and associated gene expression patterns during pollen development in Brassica napus. Plant J 11, 549-562 (1997).

42. Rodriguez-Garcia, M. I., M’Rani-Alaoui, M. \& Fernandez, M. C. Behavior of storage lipids during development and germination of olive (Olea europaea L.) pollen. Protoplasma 221, 237-244 (2003). 
43. Shockey, J. et al. Identification of Arabidopsis GPAT9 (At5g60620) as an essential gene involved in triacylglycerol biosynthesis. Plant physiology 170, 163-179 (2016).

44. Rennie, E. A. et al. Identification of a sphingolipid alpha-glucuronosyltransferase that is essential for pollen function in Arabidopsis. The Plant cell 26, 3314-3325 (2014).

45. Suzuki, M. et al. Complete blockage of the mevalonate pathway results in male gametophyte lethality. Journal of experimental botany 60, 2055-2064 (2009).

46. De Storme, N. et al. GLUCAN SYNTHASE-LIKE8 and STEROL METHYLTRANSFERASE2 are required for ploidy consistency of the sexual reproduction system in Arabidopsis. The Plant cell 25, 387-403 (2013).

47. Zhang, H. et al. Carbon starved snther encodes a MYB domain protein that regulates sugar partitioning required for rice pollen development. The Plant cell 22, 672-689 (2010).

48. Jakobsen, M. K. et al. Pollen development and fertilization in Arabidopsis is dependent on the MALE GAMETOGENESIS IMPAIRED ANTHERS gene encoding a type VP-type ATPase. Genes \& development 19, 2757-2769 (2005).

49. Koussevitzky, S. et al. Signals from chloroplasts converge to regulate nuclear gene expression. Science 316, 715-719 (2007).

50. Fukui, K., Kosaka, H., Kuramitsu, S. \& Masui, R. Nuclease activity of the MutS homologue MutS2 from Thermus thermophilus is confined to the Smr domain. Nucleic acids research 35, 850-860 (2007).

51. Fukui, K. \& Kuramitsu, S. Structure and function of the small MutS-related domain. Molecular biology international 2011, 691735 (2011).

52. Gui, W. J. et al. Crystal structure of YdaL, a stand-alone small MutS-related protein from Escherichia coli. Journal of structural biology 174, 282-289 (2011).

53. Watanabe, N., Wachi, S. \& Fujita, T. Identification and characterization of BCL-3-binding protein: implications for transcription and DNA repair or recombination. The Journal of biological chemistry 278, 26102-26110 (2003).

54. Koussevitzky, S. Signals from chloroplasts converge to regulate nuclear gene expression. Science 316, 1698-1698 (2007).

55. Hu, G. Z. \& Ronne, H. Yeast BTF3 protein is encoded by duplicated genes and inhibits the expression of some genes in vivo. Nucleic acids research 22, 2740-2743 (1994).

56. Parthun, M. R., Mangus, D. A. \& Jaehning, J. A. The EGD1 product, a yeast homolog of human BTF3, may be involved in GAL4 DNA binding. Mol Cell Biol 12, 5683-5689 (1992).

57. Rospert, S., Dubaquie, Y. \& Gautschi, M. Nascent-polypeptide-associated complex. Cell Mol Life Sci 59, 1632-1639 (2002).

58. Wiedmann, B., Sakai, H., Davis, T. A. \& Wiedmann, M. A protein complex required for signal-sequence-specific sorting and translocation. Nature 370, 434-440 (1994).

59. George, R., Beddoe, T., Landl, K. \& Lithgow, T. The yeast nascent polypeptide-associated complex initiates protein targeting to mitochondria in vivo. Proc Natl Acad Sci USA 95, 2296-2301 (1998).

60. Funfschilling, U. \& Rospert, S. Nascent polypeptide-associated complex stimulates protein import into yeast mitochondria. Mol Biol Cell 10, 3289-3299 (1999).

61. Hiei, Y., Ohta, S., Komari, T. \& Kumashiro, T. Efficient transformation of rice (Oryza sativa L.) mediated by Agrobacterium and sequence-analysis of the boundaries of the T-DNA. Plant Journal 6, 271-282 (1994).

62. Barroco, R. M. et al. The cyclin-dependent kinase inhibitor Orysa;KRP1 plays an important role in seed development of rice. Plant physiology 142, 1053-1064 (2006).

63. Zhang, D. B., Luo, X. \& Zhu, L. Cytological analysis and genetic control of rice anther development. Journal of Genetics and Genomics 38, 379-390 (2011).

64. Van Herpen, T. W. J. M. et al. Nicotiana benthamiana as a production platform for artemisinin precursors. PloS one 5, e14222 (2010).

65. Bart, R., Chern, M., Park, C. J., Bartley, L. \& Ronald, P. C. A novel system for gene silencing using siRNAs in rice leaf and stemderived protoplasts. Plant Methods 2 (2006).

66. Kouchi, H. \& Hata, S. Isolation and characterization of novel nodulin cDNAs representing genes expressed at early stages of soybean nodule development. Mol Gen Genet 238, 106-119 (1993).

67. Deblock, M. \& Debrouwer, D. RNA-RNA in situ hybridization using digoxigenin-labeled probes - the use of high-molecular-weight polyvinyl alcohol in the alkaline phosphatase indoxyl-nitroblue tetrazolium reaction. Anal Biochem 215, 86-89 (1993).

68. Nelson, T., Harpster, M. H., Mayfield, S. P. \& Taylor, W. C. Light-regulated gene expression during maize leaf development. The Journal of Cell Biology 98, 558-564 (1984).

\section{Acknowledgements}

We gratefully thank Inhwan Hwang (Pohang University of Science and Technology, Korea) for providing F1ATPase- $\gamma$ : RFP fusion construct and Tsuyoshi Nakagawa (Shimane University, Japan) for the $p G W B$ vectors. The thanks are also to Dr. Cuicui Zhang for her help in experiments. We also thank Prof. Bao-Cai Tan (Shandong University) for helpful suggestions in writing this paper. This work was supported by funds from the National Natural Science Foundation of China (Project no. 31501375) and China Postdoctoral Science Foundation Funded Project (Project no. 2016M590542).

\section{Author Contributions}

Y.-J. Liu, J. Tu and J. Zhang designed the research and wrote the article; W. Wang created the RNAi and OE lines of OsPPR676; Y.-J. Liu, X.-J. Liu, H. Chen, P. Zheng and L. Wang performed other experiments and analyzed data.

\section{Additional Information}

Supplementary information accompanies this paper at doi:10.1038/s41598-017-10727-X

Competing Interests: The authors declare that they have no competing interests.

Publisher's note: Springer Nature remains neutral with regard to jurisdictional claims in published maps and institutional affiliations.

Open Access This article is licensed under a Creative Commons Attribution 4.0 International License, which permits use, sharing, adaptation, distribution and reproduction in any medium or format, as long as you give appropriate credit to the original author(s) and the source, provide a link to the Creative Commons license, and indicate if changes were made. The images or other third party material in this article are included in the article's Creative Commons license, unless indicated otherwise in a credit line to the material. If material is not included in the article's Creative Commons license and your intended use is not permitted by statutory regulation or exceeds the permitted use, you will need to obtain permission directly from the copyright holder. To view a copy of this license, visit http://creativecommons.org/licenses/by/4.0/.

(C) The Author(s) 2017 